http://dx.doi.org/10.35381/racji.v5i3.1120

\title{
La proyección deontológica del abogado patrocinador en el proceso penal
}

The deontological projection of the sponsoring lawyer in the criminal proceedings

\author{
Alexandra Judith Andino-Guerrero \\ alexandraandino@yahoo.com \\ Universidad Regional Autónoma de los Andes, Santo Domingo \\ Ecuador \\ https://orcid.org/0000-0002-9524-1135 \\ Laura Cristina Verdezoto-Loachamin \\ lauraverdezoto@hotmail.com \\ Universidad Regional Autónoma de los Andes, Santo Domingo \\ Ecuador
}

Recibido: 31 de octubre de 2020

Revisado: 10 de octubre de 2020

Aprobado: 05 de diciembre de 2020

Publicado: 10 de diciembre de 2020 


\title{
RESUMEN
}

Partiendo de la sólida formación deontológica, ética y profesional, que debe poseer el abogado para cumplir su cometido durante el proceso jurídico, se presenta la siguiente investigación, cuyo objetivo es analizar desde un sentido crítico, jurídico y doctrinario, cómo debe proyectarse el abogado patrocinador desde lo deontológico, lo ético y lo profesional en la práctica dentro del proceso penal. Desde la perspectiva cuantitativa y el método de análisis documental, para fundamentar la investigación tomando como base diferentes fuentes documentales, la técnica para tal fin, fue el análisis de contenido bibliográfico. Como parte de la muestra poblacional, generando resultados coherentes al objetivo planteado. Se encuestaron diez abogados del libre ejercicio que han tramitado asuntos penales, para lo cual se elaboró un cuestionario. Se concluye que, en la actualidad, el ejercicio de la abogacía en Ecuador enfrenta un estado de desconfianza que de una u otra manera mella la honradez y prestigio de la profesión.

Descriptores: Deontología; derecho público; estatus profesional. (Palabras tomadas del Tesauro UNESCO).

\begin{abstract}
Based on the solid deontological, ethical and professional training that the lawyer must have to fulfill his mission during the legal process, the following investigation is presented, whose objective is to analyze from a critical, legal and doctrinal sense, how the sponsoring lawyer should be projected from the deontological, ethical and professional in practice within the criminal process. From the quantitative perspective and the method of documentary analysis, to base the research based on different documentary sources, the technique for this purpose was the analysis of bibliographic content. As part of the population sample, generating results consistent with the proposed objective. Ten free practice lawyers who have handled criminal matters were surveyed, for which a questionnaire was prepared. It is concluded that, at present, the practice of law in Ecuador faces a state of mistrust that in one way or another undermines the honesty and prestige of the profession.
\end{abstract}

Descriptors: Deontology; public Law; professional status. (Words taken from the UNESCO Thesaurus). 
Iustitia Socialis. Revista Arbitrada de Ciencias Jurídicas.

Año V. Vol. V. №3. Edición Especial. 2020-III:

Universidad Regional Autónoma de los Andes

Hecho el depósito de Ley: FA2016000064

ISSN: 2542-3371

FUNDACIÓN KOINONIA (F.K). Santa Ana de Coro, Venezuela

Alexandra Judith Andino-Guerrero; Laura Cristina Verdezoto-Loachamin

\section{INTRODUCCIÓN}

Cuando la deontología toma por objeto más delimitado de estudio los derechos y deberes concernientes al ejercicio de una profesión, apareció la expresión "Deontología Profesional", que requirió, para su aplicación práctica, la elaboración de códigos deontológicos, los cuales comenzaron a reglamentar de manera casi exacta o bien a modo de orientación, las cuestiones relativas al "deber" de los miembros de una determinada carrera o rama del saber; de ahí que se acostumbre a que sea el propio colectivo de profesionales quienes determinen dichas normas, y a su vez se encarguen de recogerlas por escrito en los códigos deontológicos.

Deontología Profesional y Ética reiteradamente son empleados como sinónimos o equivalentes, no siéndolos, lo que no es fácil comprender dada las diferencias entre ambas concepciones, las que a su vez y de conjunto, constituyen la base de su ligadura más consistente. La deontología profesional se dirige al cumplimiento del deber, se recoge en códigos deontológicos, decálogos y otros cuerpos normativos e instrumentos aprobados por los expertos, constituyendo un conjunto especializado; mientras que la ética se orienta, generalmente, al sentido del bien y de lo bueno; de aquí que no se encuentre recogida en normas, disposiciones, o compilaciones, se relaciona con lo que piensa el individuo conforme a su conciencia individual.

En la medida en que los contenidos de los códigos deontológicos se vayan interiorizando hasta convertirse en principios, valores y convicciones, de esa misma manera los miembros de la colectividad de letrados procederán de manera más cómoda y sensata de acuerdo con los esquemas que demanda la conducta social. En este sentido Pirona, Gutiérrez-Curiel \& Isea (2019) plantean lo siguiente:

El desarrollo de un ambiente ético que sea capaz de rescatar los valores y principios éticos en el potencial humano, apropiarse de la comprensión de sí, entre los actores organizacionales y con la sociedad, como un proceso de retroalimentación donde el hombre asuma el desarrollo humano siendo el centro para la transformación y promotor de los cambios profundos de su entorno, promoviendo los valores necesarios para el logro de los objetivos organizacionales centrado en la ética. (p.70) 
En la práctica de la abogacía, las políticas éticas-morales simbolizan la observancia positiva y certera de la obligación, pero en los límites que determina la normativa legal para la defensa de los bienes jurídicos de los representados, dicha actividad profesional debe ajustarse a referentes éticos, por encima de perjuicios, intereses personales, falsas convicciones o cualquier otro pensamiento. En los procesos civiles, penales, administrativos y constitucionales uno de los puntos importantes es la práctica de la prueba, es considerado el momento en el que se argumenta ante un juez la posición de las partes con elementos de evidencia y la contradicción alcanza su punto máximo. El objetivo principal del juez es obtener la verdad, por ello mientras más exigente sea el debate procesal, se obtendrá mejores recursos para dictar una sentencia justa (Bravo-Andrade y otros,2020:221)

Las personas, según lo dispuesto en el artículo 76, numeral 7 de la Constitución ecuatoriana de 2008, tienen derecho a la defensa en todas las etapas y grado del procedimiento, en tal sentido se atenderán por el defensor de su elección o por el defensor público que se designe, en tal sentido no se prohibirá el derecho a comunicarse libre y privadamente con el defensor, menos aún, que se interrogue fuera de los recintos destinados a esos efectos; así mismo el artículo 82 - El derecho a la seguridad jurídica se fundamenta en el respeto a la Constitución y en la existencia de normas jurídicas previas, claras, públicas y aplicadas por las autoridades competentes (Asamblea Nacional República del Ecuador, 2008).

De aquí que se busque recuperar la fe en la justicia, garantizando de la mejor manera a la sociedad y al Estado la protección de los derechos consagrados constitucionalmente y en Tratados Internacionales sobre Derechos Humanos en lo referente al debido proceso, de forma tal que responda a la libertad individual, dignidad humana, presunción de inocencia y especialmente al derecho a la defensa técnica.

La Defensoría Pública, como los Abogados del ejercicio privado, en atención al interés público, que es el de la realización de la justicia social para materializar sus fines, cuenta con las instituciones, principios y normativas, encaminados al desarrollo y perfeccionamiento de la abogacía exigiendo para ello una elevada formación profesional y ética, que redunde en la prestación de servicios legales de elevada 
calidad técnica. Es que la presencia del Abogado y su accionar con altos niveles de eficacia, durante la tramitación del proceso penal, resulta de mucho interés para la administración de justicia, por ser el marco en que el acusado afronta mecanismos de persecución penal, con el peligro de que sus derechos y garantías sean vulnerados, y provocar estado de indefensión (Asamblea Nacional República del Ecuador, 2018).

Es de suma importancia el rol del Abogado durante la tramitación de los procesos penales, en el sentido de amparar los intereses particulares de su defendido, en cuyo sentido deberá acudir a los medios legales a su alcance, con la más refinada técnica y sólidos principios ético-morales, colaborando así con la solución más favorable y justa para su representado. Sin embargo, Rodríguez-Camacho (2018) manifiestan:

Con apoyo de los criterios de la Corte Interamericana de Derechos Humanos, se conoce actualmente lo que podría considerarse una defensa penal manifiestamente deficiente, ineficaz, poco técnica e inoportuna, indicativos evidentes de la vulneración al derecho a la defensa, donde se citan algunos elementos como: no desplegar una mínima actividad probatoria; inactividad argumentativa a favor de los intereses del imputado; carencia de conocimiento técnico jurídico del proceso penal; falta de interposición de recursos en detrimento de los derechos del imputado; Indebida fundamentación de los recursos interpuestos; abandono de la defensa.(p.40)

Partiendo de la sólida formación deontológica, ética y profesional, que debe poseer el abogado para cumplir su cometido durante el proceso, es que se presenta el siguiente trabajo, cuyo objetivo es analizar desde un sentido crítico, jurídico y doctrinario, cómo debe proyectarse el abogado patrocinador desde lo deontológico, lo ético y lo profesional en la práctica dentro del proceso penal.

\section{METODOLOGÍA}

Se realizó el análisis documental, para fundamentar la investigación tomando como base diferentes fuentes documentales, con lo que se pretende demostrar la indefensión que ocasiona en los clientes el incumplimiento, por parte de su defensor, de sus deberes deontológicos y jurídicos como representante de sus intereses. (Lopera-Echavarría, et al.2010), la técnica para tal fin, fue el análisis de contenido 
bibliográfico, escrutando documentos, leyes, trabajos académicos, como parte de la muestra poblacional, generando resultados coherentes al objetivo planteado. Para el desarrollo de la presente investigación fueron escogidos abogados que ejercen las defensas penales, que desde ópticas diferentes pueden valorar lo que representa el buen desempeño del abogado, respecto a los intereses personales que defiende, desde lo deontológico, ético y profesional. Se encuestaron diez abogados del libre ejercicio que han tramitado asuntos penales, para lo cual se elaboró un cuestionario con 8 preguntas.

\section{RESULTADOS}

1 ¿Ha estado relacionado de alguna manera con el desempeño de algún abogado penalista?

En este sentido el encuestador procuró encuestar solo a personas que alguna vez se vieron involucrados en algún proceso penal o alguno de sus parientes cercanos, razones por las que todos respondieron afirmativamente

2. ¿Esa relación ha surgido de la tramitación de algún asunto penal suyo, de un familiar o de un amigo?

En este sentido la respuesta no fue unánime, es que seis refirieron que su relación con el abogado surgió por situaciones legales personales, mientras que los cuatro restantes se debieron a situaciones relacionada con familiares.

3. ¿Cómo fue, desde el punto de vista ético, la actuación o comportamiento del abogado durante la tramitación de la causa?

Las respuestas variaron, solo tres evalúan de buena la actuación del abogado, cuatro regular y tres malos. 
4. ¿Cuál fue su nivel de satisfacción con el servicio recibido del abogado durante la defensa del proceso penal?

Nada equilibrada la respuesta a esta interrogante, es que solo dos están muy satisfechos, tres satisfecho y cinco nada satisfecho.

5. ¿Cuáles fueron las principales faltas éticas del abogado durante la tramitación de su causa?

Aquí dos mencionaron el abandono de las causas, cuatro que el abogado le aseguró que todo saldría bien, uno que el abogado lo instó a buscar algún amigo que declarara en su favor, tres encuestados marcaron la ausencia del abogado a diligencias.

6. ¿Estableció alguna queja o denuncia en contra del abogado por alguna falta ética? Solo tres respondieron afirmativamente, mientras que siete lo hicieron negativamente. 7.En caso de que la respuesta anterior fuera positiva, ¿Cuál fue el resultado?

Los tres marcaron la opción que dice que nunca se tramitó su denuncia.

8. ¿Cómo evalúa el criterio que, sobre el ejercicio de la abogacía, existe en la ciudadanía?

Es alarmante que solo tres digan que regular, mientras que siete lo catalogan de malo.

\section{DISCUSIÓN}

Del análisis de los resultados de la aplicación de los métodos empleados para la recolección de información es posible exponer que, en su desempeño, los abogados, deben regirse por principios éticos básicos propios de su profesión para garantizar a sus patrocinados el derecho a la defensa, y es que como servidor de la justicia se deben al código de honor. Al respecto, Matus-Acuña (2007:7) habla sobre el Código de Ética, que son aplicables no en razón de la clase de procedimiento que se trate, sino de las relaciones que establecen los abogados entre sí, con 
sus clientes, con la magistratura y, en general, con la administración de justicia como función socialmente relevante.

Vale aclarar que la inadecuada actuación de los abogados atenta contra la buena administración de justicia, y es que cuando se hace uso de una prueba deformada, o falsa, además de que atenta contra el principio de justicia, en caso de no detectarse su ilicitud, también da lugar a estos sumarios disciplinarios y a retrasos en la resolución de los asuntos; de igual manera sucede cuando de mala fe el abogado no se presenta a las diligencias y obliga al órgano jurisdiccional a trasladar su práctica para una fecha posterior, entre otras artimañas utilizadas para lograr su propósito.

Al respecto Castro-Pizarro, Masache-Romero \& Duran-Ocampo (2007:38), mencionan que en distintos países existan escándalos por actos improcedentes de algunos funcionarios, debilitando la confianza de los ciudadanos hacia sus representantes; situación no ajena al contexto ecuatoriano, lo que hace que se comiencen a establecer medidas dentro de sus programas a fin de combatir la corrupción.

Cuando se valora integralmente el resultado de las encuestas realizadas a personas que han necesitado los servicios de un abogado, o alguno de sus parientes acusado por delito, se obtuvo información adversa respecto al desempeño del abogado, en su generalidad muestran la insatisfacción y lo consideran malo, algunos presentaron denuncia, pero nunca recibieron respuesta; por ello se afirma, además, presencia de irregularidades y pasividad de las autoridades facultadas para sustanciarlas. La especial misión que cumple el letrado se encuentra fundada en el respeto por la Justicia, traducido en su actuación conforme a derecho, vinculada a los principios deontológicos que sujetan el ejercicio de la profesión. El deber fundamental del Abogado, como partícipe en la función pública de la Administración de Justicia, es cooperar con ella: asesorando, conciliando y defendiendo los intereses que le sean confiados. (Merlano-Sierra, 2010:98)

Para alcanzar resultados eficaces el abogado deberá conocer, en principio, que los encargados de las diligencias primarias son la Policía, Fiscal, Peritos y Jueces, y que el Fiscal es el máximo responsable de la sustanciación del expediente investigativo, 
quien deberá practicar cuantas diligencias se requieran, en plazo breve, respondiendo de la planificación, ejecución y valoración de las acciones de instrucción, diligencias y trámites de la investigación, cumpliendo además, en el desarrollo de sus funciones, con el mandato del Juez, conforme a ley corresponde; en este sentido existe concordancia entre el Capítulo I del Título II del Código Orgánico Integral Penal, respecto al ejercicio de la acción penal que corresponde al Fiscal, y el artículo 195 de la Sección Décima, Capítulo Cuarto de la Constitución de la República del Ecuador de 2008, donde se postula que la Fiscalía General del Estado dirigirá de oficio o a instancia de parte la investigación preprocesal y procesa.

Son múltiples las diligencias que puede realizar el abogado: entrevista, como primer acto de comunicación abogado-cliente, lo que demanda mayor protagonismo y celeridad cuando el acusado está asegurado con la medida cautelar de prisión provisional; momento adecuado no solo para ahondar en los hechos objeto de inculpación, sino también para comenzar a estudiar y conocer la personalidad de su defendido. Debe actuar con un profesionalismo ético, al respecto uno de los retos a los que se enfrentan los abogados como defensores de la justicia, es el que resulta del marco normativo al que deben estar sometidos y por el que se apuesta desde la ética profesional. Cuando hacemos referencia a una conducta ética dentro del ámbito jurídico, nos referimos al comportamiento lógico y exigible que deben respetar los operadores jurídicos como profesionales al servicio de la Administración Pública de Justicia. (Santana-Ramos, 2018:28)

\section{CONCLUSIONES}

En la actualidad, ejercicio de la abogacía en Ecuador enfrenta un estado de desconfianza que de una u otra manera mella la honradez y prestigio que a través del ejercicio digno impregnaron los ilustres abogados del pasado a tan noble profesión. La proyección deontológica, ética y profesional no es otra cosa que el escudo que deberá portar el abogado en su desempeño cotidiano, rechazando cualquier tentación o instigación dirigida a infringir los deberes que le impone tan distinguida función 
social, o a realizar cualquier acción que le haga desmerecer ante la opinión pública al apartarse de los principios que sustentan la abogacía.

El mundo hoy está restringido por cambios radical en el Derecho, de igual manera ocurre con el ejercicio de la abogacía respecto a requerimientos generales sobre una nueva concepción organizativa que permita demandar del abogado una apropiada formación competitivo-ética que los categorice como apasionados guardianes de la legalidad, inclaudicables ante lo mal hecho, intensamente humanos y protectores de causas justas; proposiciones a las que se les deberá dar continuidad y seguimiento.

\section{FINANCIAMIENTO}

No monetario.

\section{AGRADECIMIENTO}

A la Universidad Regional Autónoma de Los Andes, Santo Domingo; por motivar el desarrollo de la Investigación.

\section{REFERENCIAS CONSULTADAS}

Asamblea Nacional Constituyente de la República del Ecuador, (2008). Constitución de la República del Ecuador. Montecristi. Registro Oficial 449 de 20-oct-2008. Recuperado de https://n9.cl/sia

Asamblea Nacional de la República del Ecuador. (2014). Código Orgánico Integral Penal [Comprehensive Organic Criminal Code]. Recuperado de https://n9.cl/g6sc

Bravo-Andrade J., Narváez-Zurita C., Erazo-Álvarez J., \& Pozo-Cabrera, E (2020) Vulneración del principio de contradicción para abogados ciegos en audiencias del sistema procesal ecuatoriano. [Violation of the principle of contradiction for blind lawyers in hearings in the Ecuadorian procedural system] IUSTITIA SOCIALIS.5(2),221-235. http://dx.doi.org/10.35381/racji.v5i2.743

Castro-Pizarro, J., Masache-Romero, C. \& Duran-Ocampo, A. (2007) La aplicación del Derecho Público en el Ecuador [The application of Public Law in Ecuador]. Universidad y Sociedad,11(4),350-360. http://orcid.org/0000-0003-0111-0669 
lustitia Socialis. Revista Arbitrada de Ciencias Jurídicas.

Año V. Vol. V. №3. Edición Especial. 2020-III:

Universidad Regional Autónoma de los Andes

Hecho el depósito de Ley: FA2016000064

ISSN: 2542-3371

FUNDACIÓN KOINONIA (F.K). Santa Ana de Coro, Venezuela

Alexandra Judith Andino-Guerrero; Laura Cristina Verdezoto-Loachamin

Lopera-Echavarría, J, \& Ramírez-Gómez, C, \& Zuluaga-Aristazábal, M, \& OrtizVanegas, J. (2010). El método analítico como método natural. Nómadas. [Critical Journal of Social and Juridical Sciences], 25(1).

Matus-Acuña, Jean Pierre. (2007). Control Ético y Deontología. [ Ethical Control and Ethics] lus et Praxis, 13(1), 463-472. https://dx.doi.org/10.4067/S0718$\underline{00122007000100016}$

Merlano-Sierra, J. (2010) La responsabilidad jurídica de abogados y administradores de justicia en el Derecho colombiano [Lawyer's professional liability and administrators of justicie in colombian law].Revista de Derecho. 33,96-120. Reuperado de: http://www.scielo.org.co/pdf/dere/n33/n33a05.pdf

Pirona, J., Gutiérrez-Curiel, J., \& Isea, J. (2019). Nueva visión ética en la gestión universitaria. Una mirada desde la complejidad. [ New ethical visión in university management. A look from compliance]. KOINONIA 4(8), 54-79. http://dx.doi.org/10.35381/r.k.v4i8.272

Rodríguez Camacho, M. (2018). La defensa penal eficaz como garantía del debido proceso en Ecuador. [Effective criminal defense as a guarantee of due process in Ecuador] Universidad y Sociedad, 10(1), 33-40. Recuperado de http://rus.ucf.edu.cu/index.php/rus

Santana-Ramos, E. (2018). El rol del abogado ante la ética y el ejercicio profesional. [The role of lawyer suede ethics and professional practice]. Revista de la Facultad de Derecho. 44, 1-28. http://dx.doi.org/10.22187/rfd2018n44a5 